\title{
Leriche Syndrome
}

\author{
Ibrahim Toker $^{1}$ (D), Feriyde Caliskan² ${ }^{D}$, Gullu Akbaydogan Dundar ${ }^{3}$ (D) \\ 'Department of Emergency Medicine, Mersin University School of Medicine, Mersin, Turkey \\ ${ }^{2}$ Department of Emergency Medicine, Health Sciences University Tepecik Training and Education Hospital, Izmir, Turkey \\ ${ }^{3}$ Clinic of Emergency Medicine, Mardin State Hospital, Mardin, Turkey
}

Cite this article as: Toker I, Caliskan F, Akbaydogan Dundar G. Leriche Syndrome. Eurasian J Emerg Med. $2018 ; 17$ (4): $209-10$.

A62-year-old male was admitted to the emergency department due to complain of sudden onset of weakness, pain, and hypoesthesia in the right leg. The patient's history revealed hypertension. On initial examination, patient was constantly changing postures and had a pattern of panics, his Glasgow coma scale was 15. And we found no abnormality except that the bilateral femoral pulse was absent. However, there was no coldness or paleness in the lower limbs. Additionally, his right leg experienced hypoesthesia up to the knee level. Vital findings were stable, and results of kidney and liver function tests and electrolyte levels were all within normal limits. Abdominal ultrasonography and right lower extremity
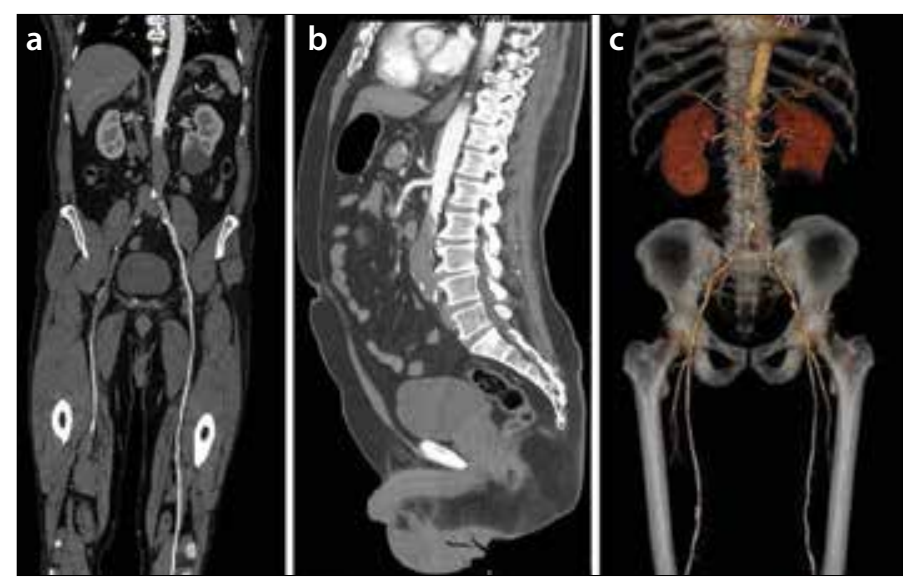

Figure 1. a-c. Coronal and sagittal view of contrast-enhanced computed tomography of the abdomen and $(a, b) 3 D$-volume rendering images showing a filling defect of the infrarenal abdominal aorta and major iliac arteries (c)
Doppler ultrasonography were also performed. A monophasic flow pattern was present in the right femoral artery and its distal part although the abdominal aorta could not be seen. We performed abdominal contrast-enhanced tomography and lowerlimb computed tomography (CT) angiography. The infrarenal abdominal aorta and major iliac arteries had a filling defect due to dense thrombus material. The patient was diagnosed with Leriche syndrome and requested a cardiovascular surgical consultation; hence, he was admitted to a cardiovascular surgery clinic. Anticoagulant therapy was initiated, and an elective operation was discussed and planned.

\section{Discussion}

Leriche syndrome is an aorta-iliac occlusive disease resulting from thrombotic occlusion of the region just above the abdominal aorta bifurcation (1). The classic triad is hip and throat claudication, absence of the femoral pulse, or general weakening and impotence. It can have atypical presentations, such as renal infarction (2).

Leriche syndrome is named after René Leriche, the famous French surgeon who performed the first operative treatment for this disease. Leriche syndrome is more common in smokers, in patients of hypercholesterolemia, and in those with peripheral arterial disease (3). For the diagnosis of Leriche syndrome, ankle brachial index measurement, duplex Doppler ultrasonography, and CT angiography are important imaging modalities. Conventional surgical treatment for aortoiliac occlusive diseases include aortoiliac endarterectomy and aortobifemoral bypass. For high-risk patients, axillofemoral

ORCID IDs of the authors: I.T.0000-0002-5346-2116; F.C. 0000-0002-4414-4757; G.A.D. 0000-0002-6565-6209. 
bypass (extra-anatomic technique) and percutaneous angioplasty are also viable alternatives $(2,3)$

Informed Consent: N/A.

Peer-review: Externally peer-reviewed.

Author Contributions: Concept: I.T.; Supervision - I.T.; Data Collection and/or Processing - F.C., G.A.D.; Analysis and/or Interpretation - I.T.; Literature Search - F.C., G.A.D.; Writing Manuscript - I.T.; Critical Review - I.T.

Conflict of Interest: The authors have no conflict of interest to declare.
Financial Disclosure: The authors declared that this study has received no financial support.

\section{References}

1. Seyithanoglu M, Gundag M, Dogan K, Kitis S, Aydin T, Peru C. Leriche syndrome with lumbar disc hernia: first case report in literature. J Neurol Sci. 2012; 28: 641-5.

2. Lin CW, Liu CY, Chen $\mathrm{CH}$. Acute renal infarction: an atypical presentation of Leriche syndrome. Intern Med. 2012; 51: 2485. [CrossRef]

3. Lee WJ, Cheng YZ, Lin HJ. Leriche syndrome. Int J Emerg Med. 2008; 1 : 223. [CrossRef] 